\title{
Resenha
}

\section{O Mistério do Simonal}

ALEXANDRE, Ricardo. Nem vem que não tem: a vida e o veneno de Wilson Simonal. São Paulo: Editora Globo, 2009.

Petrônio Domingues

Doutor em História (USP)

Professor da Universidade Federal de Sergipe (UFS)

Não é possível reconstituir a história da música popular brasileira sem fazer menção a Wilson Simonal, um negro que, no auge de sua carreira, nos anos de 1960, era um dos cantores mais populares do País. Fenômeno de sucesso e fama, idolatrado por milhares de fãs, disputado pelas grandes gravadoras e emissoras de televisão, encenando shows concorridíssimos e interpretando uma música que despertava vibração, fascínio e emoção, seu nome era sinônimo de estar na moda, ter estilo e irradiar coisas boas: energia positiva, talento e muita alegria. Ser um Simonal, naquele contexto, era o sonho de qualquer ser humano que vivesse no "país tropical". Na década de 1970, o cantor caiu em descrédito e, nas décadas de 1980 e 1990, quando morreu, jazia no ostracismo. Sua música já não mais encantava. Rejeitado pelas gravadoras, perseguido pela imprensa e esquecido pelo grande público, seu nome era associado a coisas ruins: delação, decadência e ressentimento. Ironicamente, ninguém mais queria ser um Simonal. Qual o mistério que envolveu a ascensão e queda do maior "showman brasileiro"? Como a opinião pública aprendeu a amálo e, depois, a preteri-lo? Em síntese, qual a trajetória de vida de Simonal? São essas as questões, relacionadas à biografia desse vulto da música popular brasileira, que motivaram o livro Nem vem que não tem: a vida e o veneno de Wilson Simonal, do jornalista paulista Ricardo Alexandre.

Fruto de dez anos de pesquisa, o livro está dividido em sete capítulos. No primeiro - intitulado O "Pai João" (1938-1960) -, o autor aborda aspectos da infância, adolescência e parte da juventude de Simonal. Filho de Maria Silva de Castro, uma cozinheira negra, mineira e analfabeta, que se radicou no Rio de Janeiro, e de Lúcio Pereira Castro, um radiotécnico mulato, também mineiro, Wilson Simonal de Castro nasceu no bairro da Cidade Nova, na capital fluminense, na madrugada chuvosa de 23 de fevereiro de 1938, em plena época em que a cidade era palco de desfile de blocos e se via contagiada com a alegria 
dos foliões do carnaval. Seu nome foi homenagem a um jovem ginecologista que acompanhou o parto. Desde a tenra idade, Simonal acompanhou as crises no relacionamento dos pais, até que se deu a separação. Meses depois, Lúcio procurou Maria e, após uma conversa, reataram o relacionamento. Foi nessa época que Simonal recebeu da mãe o apelido de "Pai João", assim como foi nessa época que ele ganhou mais um irmão. A chegada do segundo filho não foi suficiente para manter o pai em casa. Lúcio acabou com o casamento; desta vez, definitivamente. Se a situação já era difícil, sem o provedor da família tornou-se caótica. Para conseguir sobreviver, Maria trabalhou como cozinheira em casas de família. Com poucos recursos, ela e os dois filhos moravam num barraco, na favela da Praia do Pinto, no Leblon. Foi naquele ambiente de pobreza que Simonal experimentou muitas humilhações, enfrentou o problema do racismo e se submeteu a vários tipos de privação. Estudou graças à ajuda de terceiros, mas não por muito tempo, pois teve que trabalhar para ajudar no orçamento de casa. Alistou-se no Exército e prestou o serviço militar. Foi no quartel que ele fez as primeiras apresentações como cantor. Sua performance arrancava elogios, inclusive, do comandante. Motivado, Simonal montou o Dry Boys - seu primeiro grupo musical, que se apresentava em pequenas festas, eventos e programas de televisão - e decidiu pedir baixa da carreira militar, em 1960. Devido às divergências de seus integrantes, o Dry Boys se extinguiu no ano seguinte. Simonal, porém, continuou investindo no sonho de brilhar como artista. Trabalhou em diversos lugares de dia, pois, à noite, perambulava pelas boates e clubes atrás de alguma chance como cantor. Até o fim de 1960, sua vida foi um mar de dificuldades.

No segundo capítulo do livro - denominado O Frank Sinatra do Beco das Garrafas (1961-1965) -, o autor narra como Simonal iniciou sua meteórica ascensão no show business brasileiro. Quem lhe deu uma força, nessa fase, foi Carlos Imperial, um então apresentador de programa musical na TV Guanabara, produtor cultural e descobridor de grandes talentos. Imperial tinha grande influência no meio artístico e contratou Simonal, a princípio, como ajudante do programa de televisão, para depois incentivá-lo na faina de crooner, na rede de bares, boates e restaurantes da noite da Zona Sul carioca. Por fim, Imperial foi decisivo para seu "cupincha" assinar um contrato com a gravadora Odeon, por cinco anos. Simonal entrou no estúdio em novembro de 1961, para gravar um single. Dois anos depois, lançou o seu primeiro LP, Wilson Simonal tem algo mais. Cantor versátil e eclético, Simonal significava a "autêntica" conexão entre o morro e o asfalto, cantando, nessa primeira fase, músicas de uma bossa-nova renovada, com voz poderosa, quente e sincopada. Sua carreira, entretanto, só decolou quando ele se apresentou nos palcos do 
Beco das Garrafas, em Copacabana. Foi ali que, entre 1964 e 1965, Simonal ganhou sofisticação e cultura musical, aprendeu a explorar o palco e entendeu rapidamente a diferença entre boa música e bom espetáculo. As canções de seu segundo álbum, $A$ nova dimensão do samba, considerado até hoje um marco na música moderna brasileira, definiram o seu estilo inconfundível: o "suingue", um ritmo musical contagiante, que reunia elementos do jazz repleto de balanço, feito para dançar por big bands, do samba e das baladas românticas. Simonal chegou a receber a alcunha de "Frank Sinatra do Beco das Garrafas", mas o "rótulo" que nele vingou foi de "rei do suingue". Tudo por causa de sua grande voz e de uma capacidade de improvisar e de reinventar a melodia vocal, nunca vista antes, mantendo a prosódia da letra e adicionando um "molho" todo especial, que foi chamado de "champignon". Foi nesse momento que a carreira artística de Simonal se desdobrou, com shows em teatro, excursão ao exterior, aparições em programas de televisão, gravações de novos álbuns, assim como foi nesse momento que ele se casou com Tereza Leite Pugliesi, uma jovem loira de família de classe média, com quem viria a ter três filhos: Wilson Simonal Pugliesi de Castro (que hoje é cantor, adotando o nome artístico de Wilson Simoninha), Patrícia Pugliesi de Castro e Maximiliano Simonal Pugliesi de Castro (que também segue a carreira do pai, usando o nome Max de Castro).

No terceiro e quarto capítulos - intitulados O showman (1966-1969) e O garotopropaganda (1969-1971) -, Ricardo Alexandre relata como, ao longo da segunda metade da década de 1960, a carreira artística de Simonal ascendeu numa escala exponencial. O novo showman, que nos palcos cantava, dançava e interagia com o público, numa atmosfera de absoluta sinergia, foi contratado para comandar o programa - o Show em Si...monal - na poderosa TV Record; estreou novos espetáculos para teatro, no Brasil e exterior - em países como Portugal, Espanha, México, Alemanha, Itália, Argentina, Colômbia e Peru -; participou dos festivais de música popular brasileira; tornou-se garoto-propaganda da Shell, assinando o mais fabuloso contrato de publicidade já consignado no Brasil. E inaugurou um estilo musical próprio, que misturava o "samba jovem" - posteriormente rebatizado de "samba-rock" -, e o boogaloo, o jazz latinizado, produzido para as pistas de dança por portoriquenhos e cubanos de Nova York; tudo com um tempero pop e muito "veneno", como dizia. Todos sabiam que estavam diante de algo novo. Ou, nas palavras de um músico da época, "não era iê-iê-iê, não era bossa-nova, não era canção de protesto, não era jaž, mas era tudo isso e era algo completamente diferente" (p. 89). A partir dali, Simonal emplacou um hit atrás do outro, como: "Mamãe passou açúcar em mim”, "Meu limão, meu limoeiro", "Carango", "Nem vem que não tem", “Tributo a Martin Luther King”, “Sá Marina”, 
"Zazueira", "País tropical", entre outros. O cantor se transformou em ícone. Além das "roupas, do sorriso, da voz e de acessórios como o boné e os óculos, havia as gírias que ele lançava ou reverberava em seu programa". Algumas eram inspiradas no meio musical, outras ele ouvia na rua e outras ainda eram "inventadas por ele ou por Carlos Imperial. Todas eram imitadas por fãs do Brasil inteiro e algumas sobrevivem até hoje no nosso vocabulário". Dotado de uma magia incomensurável, Simonal tornou-se "simplesmente" o maior artista do Brasil (pp. 147-148). Enquanto Roberto Carlos vendia, em 1969, 300 mil discos, o astro afro-brasileiro vendia entre 500 e 600 mil. Nas palavras de Nelson Mottta, ele era "tão popular quanto a seleção [brasileira de futebol, que conquistou a Copa do Mundo de 1970] e nas ruas dava mais autógrafo do que Pelé" (p. 167). Quando o sucesso, a fama e o dinheiro pareciam ser eternos, veio a derrocada. No momento mais extremo do regime militar, em meio ao clima de caça às bruxas, Simonal passou a cantar músicas de apelos ufanistas, o que agradou os ditadores de plantão, mas desagradou tremendamente a imprensa, cujos profissionais eram, em sua maioria, ligados à esquerda. Para piorar, o cantor brigou com a cúpula da emergente TV Globo, cancelando sua participação no Festival Internacional da Canção de 1970. Todavia, o estopim de tudo foi o episódio envolvendo um dos funcionários da Simonal Produções.

No quinto e sexto capítulos - chamados O criminoso (1971-1975) e O proscrito (19751993) -, o autor narra a ruína de Simonal. Desconfiado de que Raphael Viviani, seu "excontador", estava desviando recursos da empresa - a Simonal Produções Artísticas -, o cantor resolveu procurar seus "amigos" policiais do DOPS para apurar os fatos. Estes então foram até a casa do ex-contador e o obrigaram a ir até o escritório da Simonal Produções, onde Simonal os aguardava. $\mathrm{Na}$ sala de reuniões da empresa, os policiais queriam que Viviani admitisse oficialmente que havia desfalcado o caixa numa quantia equivalente a mais de 500 dólares semanais. O ex-contador se recusou a fazer qualquer tipo de confissão. Diante disso, foi conduzido até a sede do DOPS, no centro do Rio de Janeiro, onde foi torturado e obrigado a redigir uma confissão de culpa. Viviani foi liberado. Quando chegou em casa, decidiu registrar queixa contra o cantor e procurar a imprensa. O assunto ganhou destaque nas páginas policiais dos principais jornais. Em face da repercussão, o diretor de Divisão de Operações do DOPS determinou a abertura de sindicância. O problema, nessa altura, adquiriu uma nova dimensão. Em vez do desfalque nas contas da Simonal Produções, a preocupação passou a ser: por que um "contador" foi torturado numa delegacia montada pelo governo para investigar crimes contra a segurança nacional? E por que o DOPS destacou seu pessoal e seu equipamento, "que deveriam 
estar protegendo o país da 'ameaça terrorista', para resolver um problema contábil de um cantor pop" (p. 204)? Para responder a essas questões, Simonal apresentou um termo de declaração, em que comunicava ter recebido telefonemas anônimos, os quais sempre ameaçavam de sequestro a sua pessoa e os seus familiares caso não fosse feita "uma certa injunção com o possível grupo subversivo em nome do qual o anônimo falava". O declarante não vinha dando importância aos telefonemas, porém o tom ameaçador com que era feita essa nova ameaça e a semelhança de voz do anônimo com a de seu exempregado Raphael Viviani o levaram a pedir ajuda aos agentes do DOPS. Tudo foi forjado; tudo parecia perfeito, entretanto falhou. O último parágrafo do documento comprometia a imagem pública do cantor: "Wilson Simonal aqui comparece visto a confiança que deposita nos policiais aqui lotados e visto aqui cooperar com informações que levaram esta seção a desbaratar por diversas vezes movimentos subversivos no meio artístico". Por incrível que pareça, Simonal assinava um documento em que declarava "cooperar com informações" com o DOPS, informações estas que levaram o órgão de repressão a "desbaratar por diversas vezes movimentos subversivos no meio artístico". Não tardou para a declaração vir a público. A partir dali, o cantor foi impiedosamente perseguido pela imprensa, caindo em descrédito e carregando, para o resto da vida, o estigma de delator de colegas da esquerda, dedo-duro dos artistas. O fato é que sua carreira entrou em franco declínio. Mudou de gravadora, mas o novo repertório, notadamente de samba-rocks, já não fazia o mesmo sucesso de massa de outrora. Investiu no samba. Também não houve boa aceitação. Para complicar, Simonal passou a ser vaiado nos shows. Repudiá-lo, naquele contexto, adquiriu um sentido simbólico de resistência contra a ditadura. Com a imagem pública chamuscada, contratos publicitários foram cancelados. Emissoras de TV, como a Globo, e rádio vetavam o seu nome. Muitos teatros e grandes casas de espetáculos boicotavam-no. Uma sucessão de acidentes, tragédias e infelicidades ao longo da década de 1970 marcaram, peremptoriamente, a queda do maior showman do Brasil.

Nos dois últimos capítulos do livro - designados de $O$ proscrito (1975-1993) e $O$ sobrevivente (1993-2000) -, Ricardo Alexandre relata as melancólicas tentativas de reabilitação de Simonal no show business brasileiro, até o final da sua vida. Quase tudo em vão. A imprensa e os formadores de opinião não perdiam a oportunidade de atacar o cantor. Sua carreira foi ceifada pelo estigma de dedo-duro, na década de 1980. É dessa época o pungente desabafo: "Sou um exilado dentro do meu próprio país. Falam em direitos humanos, em democracia, em entulho autoritário, mas acusam-me por ouvir falar; o ódio 
permanece impune, o patrulhamento sobrevive" (p. 272). Sem gravadora, patrocinadores e espaço na mass media (rádio e TV), os espetáculos de Simonal ficaram cada vez mais esporádicos. É verdade que ele jamais ficou em inatividade, não obstante seus shows ocorriam apenas no circuito marginal: em palcos de pequeno e médio porte, em clubes no subúrbio ou mesmo nas feiras de frutas no interior, exposições de gado, convenções de empresas e festas-baile, quando satisfazia um público mais maduro, que tinha saudade dos tempos áureos do astro pop. Depois de um compacto publicado no início de 1984, Simonal passaria mais de dez anos sem lançar um novo disco nas lojas brasileiras. Na década de 1990, seu nome foi banido dos jornais, revistas e programas de televisão, até cair no esquecimento. Aquele que foi um dos rostos mais conhecidos do Brasil já podia andar pelas ruas de São Paulo, onde passou a residir, quase que anônimo. Isolado, longe da vida de glamour, sem fama, prestígio, passou a enfrentar dificuldades financeiras. Para agravar de vez a situação, sucumbiu ao alcoolismo. Foi à sarjeta. "A partir de 1991", escreve o autor, "cada vez mais deprimido, sem forças e sem voz, sua vida se resumia a beber". Com os três filhos adultos e a esposa com problemas psiquiátricos, Simonal "perdeu os pudores em passar a noite fora bebendo cachaça ou cerveja, ou em ter de ser carregado pelos filhos para o elevador nas primeiras horas da manhã" (p. 278). Depois de alguns internamentos decorrentes da cirrose hepática e ficar, desesperadamente, tentando provar não ter sido dedo-duro da ditadura, Simonal faleceu no dia 25 de junho de 2000, aos 62 anos.

Ricardo Alexandre encerra o livro fazendo um balanço crítico da suposta colaboração de Simonal com os órgãos de repressão da ditadura. Mesmo sendo uma questão controversa e espinhosa, o autor apresenta argumentos plausíveis. Simonal não foi vítima de uma conspiração maquiavélica, mesmo porque ele não era nenhum alienado. Segundo César Camargo Mariano, seu amigo, Simonal só falava sobre duas coisas: música e mulher. Nunca falava sério sobre nada, nem política, nem religião. Para dizer o que pensava, sempre recorria à blague, à chacota, à piada. Ele era brincalhão, divertido, afirma Mariano. O único assunto que abordava com alguma seriedade era a questão racial. Mas mesmo ali ele era superficial (p. 114). Isto não significa dizer que Simonal era alheio à vida política e um ignorante dos rumos da direita e esquerda brasileiras. Como aponta Alexandre, o cantor era simpático ao golpe de 1964. Ele próprio admitiu: "Não havia outra saída [além do golpe militar]. Não tínhamos nenhuma liderança política. Nada mais correto do que os militares assumirem o poder em um momento de caos” (p. 176). Defender essa posição publicamente causou grande revolta na esquerda, inclusive entre os artistas, conquanto não era coisa de alienado. Por outro lado, rotular Simonal como sendo de 
direita é igualmente equivocado. No dia 11 de novembro de 1970, em uma apresentação na convenção final do MDB, partido de oposição ao governo militar, o cantor declarou publicamente que, nas eleições do dia 15, votaria nos senadores e deputados de oposição. Poucos eram os artistas que declaravam seus votos na época (é de Chico Buarque a "bela" frase: "entre MDB e Arena, sou Fluminense"). Mas Simonal, afirma Alexandre, "era o homem que fez um discurso contra o Comando de Caça aos Comunistas, que levava cartas aos exilados na Europa e que recitou em seus shows trechos de 'A mais-valia vai acabar', seu Edgar, de Vianinha. Em que, em 1979 declarava que 'o MDB e a Arena são uma farsa, é preciso criar o Partidos dos Trabalhadores"' (p. 177).

Se há evidências de alinhamento do cantor com o DOPS, não se sabe até hoje, afirma o autor, como isso se dava. Após 40 anos da implantação da ditadura militar no Brasil, não apareceu nenhuma pessoa que tenha sido denunciada nem "movimento" que tenha sido "desbaratado" por Simonal. O promotor do caso Viviani, Antonio Carlos Biscaia, em entrevista para o autor, disse "que ninguém poderia pedir um favor ao DOPS como fez Simonal se não tivesse algum grau de intimidade com a polícia política da época. Mas ele mesmo, em seguida, admite que em nenhum momento do processo, nem entre acusadores nem entre defesa, houve qualquer prova concreta de que essa tal colaboração era delação" (p. 334). Segundo Alexandre, há razões para acusar Simonal de ter sido usado pela direita, bem como há motivos para pensar que ele foi crucificado pela esquerda, mas a única certeza é de que o cantor afro-brasileiro era - e sempre foi - "fruto híbrido em tempos de contrastes", um "personagem multifacetado em tempos de ídolos unidimensionais". Roberto Carlos seria o genro que toda mãe queria ter, bom moço e galã. Por seu turno, Simonal era, a um só tempo, mocinho e vilão, elegância e avacalhação, direitos civis e pilantragem, convenção do MDB e reunião no DOPS. Como ele próprio se identificou certa vez, "como artista, sou um paradoxo". Não à toa, afirma o autor, "Simonal só voltou a fazer sentido em tempos em que os absolutos são questionados, em que um governo de ex-guerrilheiros é investigado pelos mesmos escândalos de corrupção de governos anteriores, em que Lula sobe ao palanque com Fernando Collor de Mello. Wilson Simonal já era esse futuro esquisito em 1968” (pp. 334-335).

Ricardo Alexandre tem razão em algo: Simonal deve ser visto antes como um camaleão, um sujeito que, ao longo da vida, forjou identidades fluidas, descentradas e fragmentadas, sem respeitar coerências estéticas, padrões culturais uniformes e lealdades político-ideológicas esquemáticas ou maniqueístas. Como artista versátil e criativo, ele se inventava e se reinventava conforme o cenário, as narrativas e os sujeitos de cada contexto. 
No entanto, quando analisa o processo de condenação moral de Simonal, o autor não confere, a meu ver, a devida importância para o problema do racismo. Se a sua condição de um negro diferenciado não é suficiente para explicar o porquê ele foi o único caso de "colaborador", qualquer que tenha sido sua colaboração, a ser punido publicamente pela ditadura militar, o fator racial não pode ser negligenciado desse processo. Ninguém discute que Simonal era um talento ímpar; seu "suinge" colocava para dançar, numa mesma pista, a socialite e sua faxineira. Sua habilidade de comandar a plateia como se fosse seu próprio coral de apoio, tanto em uma casa de show da moda, como em seu programa na TV Record, em teatro ou no Maracanãzinho, impressionava a todos. No ápice de sua carreira, ganhou respeito da crítica, despertou os olhares do grande público, atraindo milhares de fãs, e conquistou a confiança da mass media. Mas isso não bastava. Ele era um negro, cuja postura de altivez e garbo e estilo heterodoxo - que o cantor gostava de chamar de "pilantragem"" - provocavam grandes incômodos e, em alguns aspectos, significavam uma afronta ao status quo.

Portanto, qualquer explicação que busque decifrar o mistério que envolveu a ascensão e queda do maior "showman brasileiro" deve levar em conta as múltiplas variáveis em jogo. Sem abordagens reducionistas, pode-se dizer que suas ações escusas só adquiriram aquela dimensão (negativa) devido a uma conjugação de fatores, como questão racial, inveja, idiossincrasias e a conjuntura histórica polarizada. Para a "boa sociedade" brasileira, não era fácil "engolir" um sujeito que, do anonimato, tornou-se o primeiro negro a apresentar sozinho um programa de televisão no país - o Show em Si...monal. Um negro que, de crooner, acabou duetando com Sarah Vaughan e arrancando elogios de Quincy Jones, em Paris. Um negro que, de ex-favelado, tornou-se empresário, montando seu próprio escritório para ter controle total de sua carreira. Um negro que foi o maior protagonista de peças publicitárias de uma multinacional do setor pretolífero e adorava ostentar poder econômico: roupas caras, compradas em lojas suntuosas; carros importados (como uma

\footnotetext{
${ }^{1}$ Em 1970, Simonal concedeu uma entrevista para um órgão da grande imprensa e explicou como moldou o seu estilo: "Um dia, fui assistir a um filme do Sean Connery, um desses 007 contra uma chantagem qualquer, na última sessão de sábado. O cinema estava duro de tanta gente, não tinha lugar nem no banheiro e eu tive de ficar driblando uma coluna até o filme acabar. Eu estava certo que o cinema estava cheio de mulher para ver 007, mas quando a luz acendeu tinha $80 \%$ de homens. Aí eu me perguntei, 'como é que é?'. E comecei a descobrir que o 007 faz aquele gênero que todo homem gostaria de fazer. Ele não é bonito. Pode ser um tipo de machão, mas isso não é difícil de ser. Conquista todo mundo, bate a torto e direito, é polícia, mas transgride a lei e ainda leva esculacho. É um irreverente, um irresponsável. Foi lá na Rússia e atacou a embaixatriz; tem reunião e ele chega atrasado, com aquela roupa. Os outros de terno azul-marinho e camisa branca, e ele chega de azul-claro e camisa cor-de-rosa. Uma pasta diferente, um ar cínico. Todo mundo se projeta nele, e foi aí que eu senti que dava pé. Uma certa irreverência, um certo cinismo, mas ao mesmo tempo, uma aura de simpatia para que todos estejam na sua e você acaba sendo aquele cara que todo mundo queria ser". Jornal do Brasil. Rio de Janeiro, 24 de fevereiro de 1970 apud Alexandre (2009:99).
} 
Mercedes do ano, vermelha e preta, como o Flamengo, seu time do coração), que frequentava ambientes sofisticados e só tomava uísque importado. Um negro de personalidade forte, que falava publicamente do problema do racismo, numa época em que esse era um assunto tabu. Um negro, digamos, abusado, que declarava para a imprensa no auge da fama e riqueza: "carros, mulheres, caviar... Mulheres, carros... Minha vidinha está ficando monótona” (p. 120). Um homem negro, por quem as loiras da alta sociedade suspiraram. Em síntese, Simonal foi um "crioulo" que não soube se colocar em seu devido lugar na sociedade. O fato de ser negro depunha contra ele, na medida em que, do ponto de vista simbólico, sua postura altaneira colocava em cheque o status quo racial brasileiro, mas sua personalidade difícil, o despeito de muitas pessoas e o clima de patrulhamento ideológico, de maniqueísmo político, típico dos anos de chumbo, também ajudaram na sua sentença condenatória, sem direito à anistia.

O livro Nem vem que não tem padece de alguns (poucos) problemas. A narrativa é, em certos momentos, demasiadamente descritiva e factual, com o autor arrolando determinados acontecimentos e eventos reiteradamente, sem a preocupação de estabelecer conexões com as tramas e os contextos mais amplos nos domínios político, social, cultural e econômico. Talvez isso ocorra porque Ricardo Alexandre seja um jornalista e, por conseguinte, não denota as preocupações típicas do métier dos historiadores. Essa assertiva fica reforçada quando se constata que a obra é desprovida de diálogo historiográfico e há pouco rigor na apresentação das fontes. Muitas das fontes consultadas (e citadas) não são referenciadas. Isto, contudo, não compromete a qualidade de um livro que em 2010 já foi premiado pelo Prêmio Jabuti, o maior prêmio da literatura nacional, na categoria de "biografia". A quantidade de fontes, a riqueza informativa, a qualidade das imagens, o esmero gráfico da obra e a sensibilidade do autor saltam aos olhos do leitor. Não se trata de uma narrativa insípida, mas fluente e apaixonada. Se Wilson Simonal morreu com a pecha de alcaguete da ditadura militar e, em função disso, teve sua contribuição apagada da memória oficial da música brasileira - como se milhões de discos não tivessem sido vendidos, milhões de pessoas não tivessem cantado com ele nos shows, nem o assistido pela televisão -, com a leitura de Nem vem que não tem não dá para ficar indiferente às contradições de Clio e repensar as (in)justiças de Mnemósine. 